\title{
THE EFFECT OF GENDER AND VETERAN STATUS ON THE LEVEL OF PERCEIVED STIGMA SURROUNDING PTSD
}

\author{
A Thesis \\ presented to \\ the Faculty of California Polytechnic State University, \\ San Luis Obispo
}

\author{
In Partial Fulfillment \\ of the Requirements for the Degree \\ Master of Science in Psychology
}

by

Ryan Everett Lubock

May 2017 
(C)2017

\section{Ryan Everett Lubock}

ALL RIGHTS RESERVED 


\section{COMMITTEE MEMBERSHIP}

TITLE:

The Effect of Gender and Veteran Status on the Level of Perceived Stigma Surrounding PTSD

AUTHOR: $\quad$ Ryan Everett Lubock

DATE SUBMITTED: $\quad$ May 2017

COMMITTEE CHAIR: Michael Selby, Ph.D.

Professor of Psychology

COMMITTEE MEMBER: J. Kelly Moreno, Ph.D.

Professor of Psychology

COMMITTEE MEMBER: Taylor Smith, Ph.D.

Professor of Psychology 


\begin{abstract}
The Effect of Gender and Veteran Status on the Level of Perceived Stigma Surrounding PTSD Ryan Lubock
\end{abstract}

This paper explores how gender and veteran status effects the level of stigmatization around Posttraumatic Stress Disorder (PTSD). Participants were randomly assigned to one of four vignette conditions, which were distinguished by gender and veteran status. Participants were then asked to rate how they perceived the individual depicted in the vignette. The researchers analyzed the results by examining how the participants own report of gender, and masculinity, effected how each of the vignettes were judged. This paper addresses the stigma surrounding mental health in general, and more specifically how that stigma affects individuals suffering from PTSD across multiple domains. For the purposes of this paper, the domains of stigma explored include public stigma, social distancing, self-stigma and gender role conflict. Research indicates that PTSD is detrimental to both males and female veterans and civilians. In general, research suggests that males are more stigmatized than females and less likely to seek treatment (Addis \& Mahalik, 2003; Good, et al., 1995). Individuals with a PTSD diagnosis may not seek services due to self-stigma, public-stigma, and social distancing (Corrigan \& Watson, 2002; Girma et al., 2013; Gulliver et al., 2010; Link et al., 2002; Vogel et al., 2006; Weiner et al., 1988). Women are also more likely to be diagnosed with PTSD than men, and veterans are more likely to be diagnosed with PTSD than civilians (Breslau, 2001; Kessler et al., 1995; Olff et al., 2002). Although women are diagnosed with PTSD more frequently than men, research indicates that male veterans are the most stigmatized (Daoud, 2009; Mittal et al., 2007). 


\section{ACKNOWLEDGMENTS}

This work is dedicated to all those impacted by the stigma surrounding mental health, to the men and women who serve our country in the armed forces, and to all those struggling with PTSD. I would like to thank my brother, Nathan, for his support, mentorship and guidance both academically and in life. Thank you for all that you do for me. I would also like to thank Dr. Selby for the sacrifices he made to help guide me through this process. Finally, I would also like to thank Dr. Moreno, and Dr. Smith for their help, and correspondence through this process. 


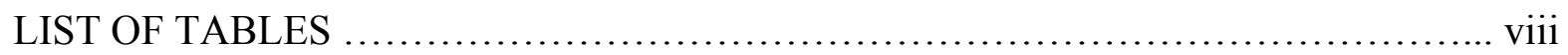

LIST OF FIGURES .............................................................. ix

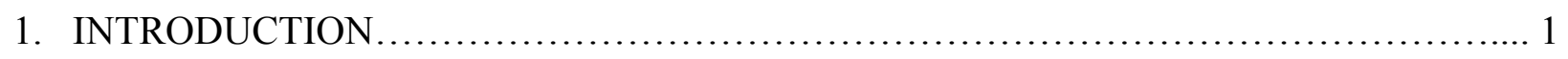

Stigmatization and Mental Health ........................................... 2

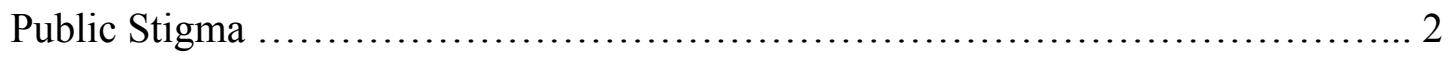

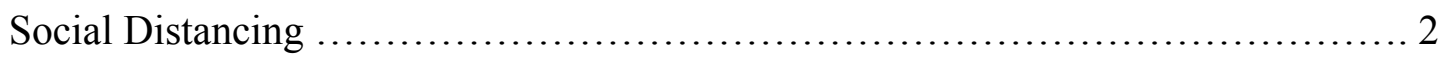

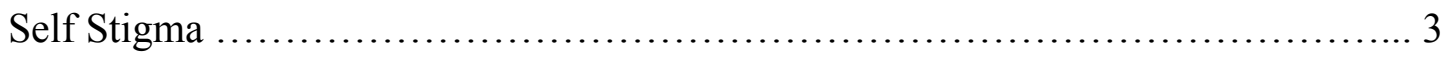

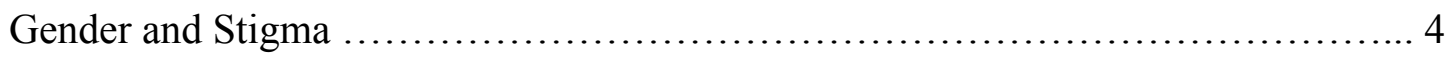

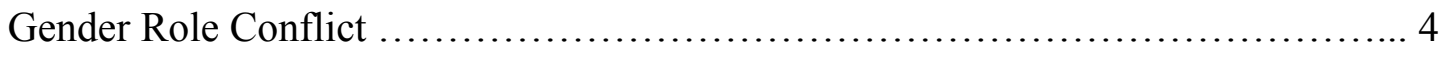

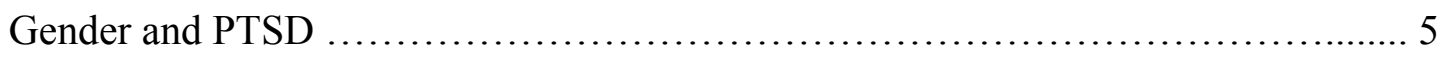

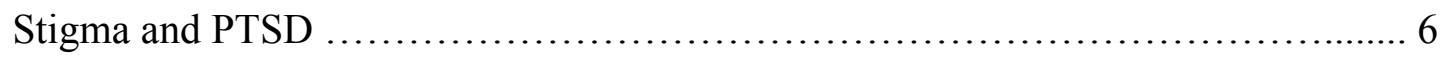

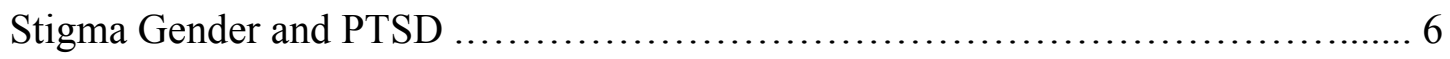

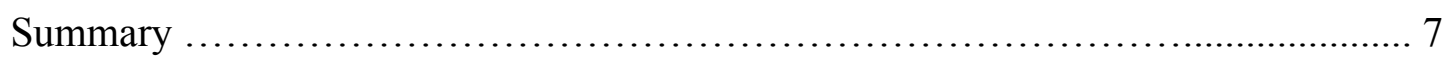

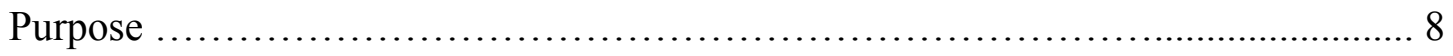

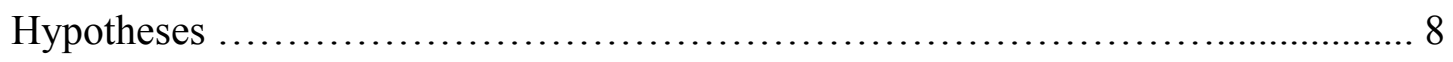

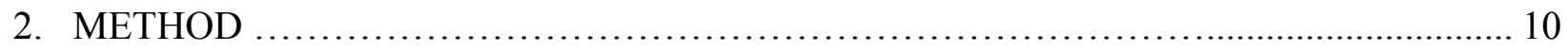

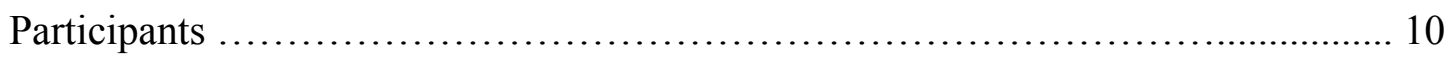

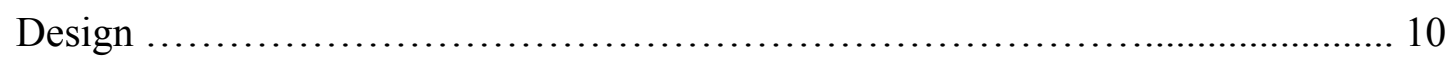

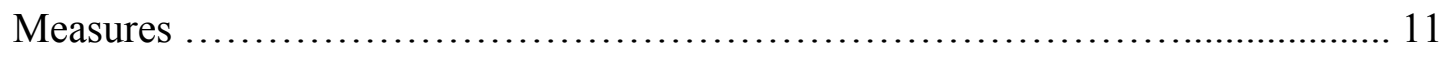

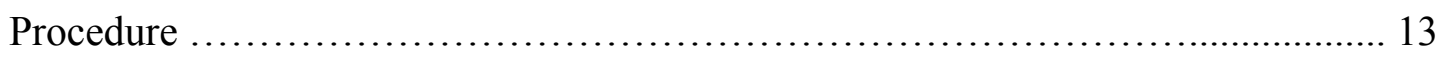

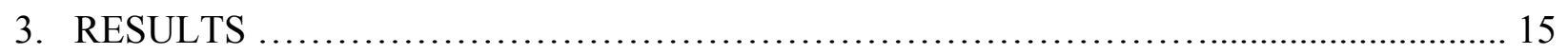


Descriptive Statistics ................................................................. 15

Crowne-Marlow Social Desirability Scale ................................... 16

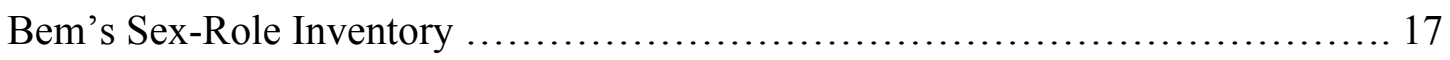

Perceived Dangerousness .......................................................... 19

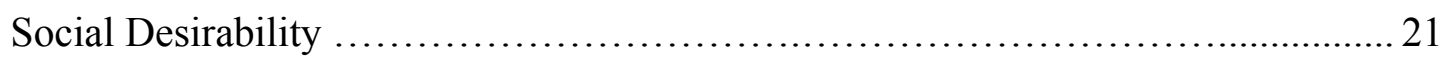

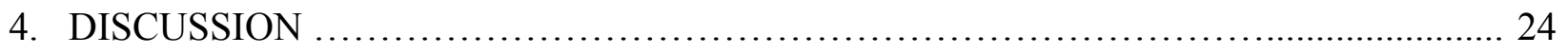

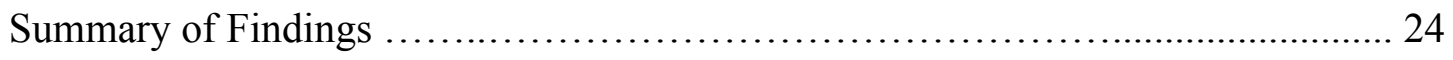

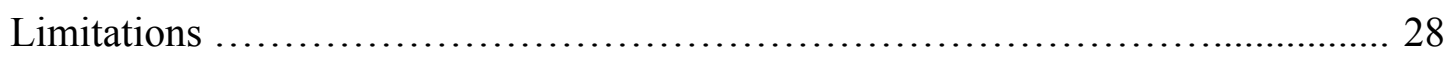

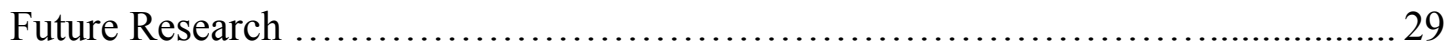

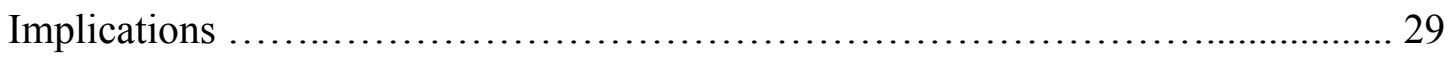

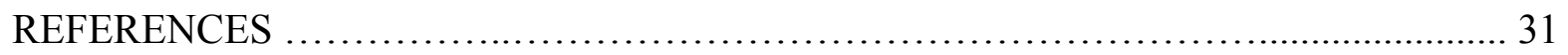

\section{APPENDICES}

A. Crowne-Marlow Measure of Social Desirability Scale............................. 37

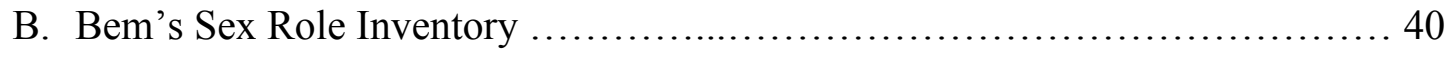

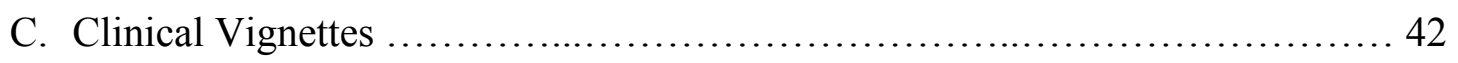

D. Measures of Social Distancing .............................................. 45

E. Measures of Perceived Dangerousness ...................................... 47

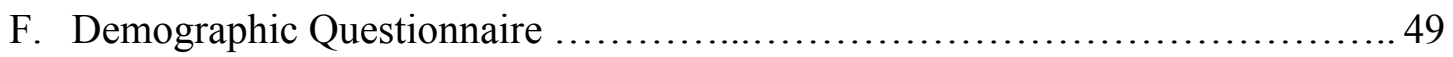

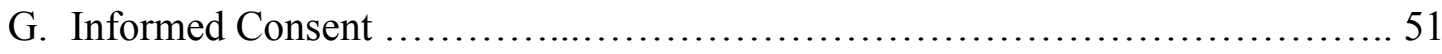

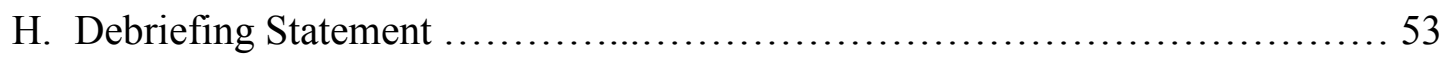




\section{LIST OF TABLES}

Table Page

1. Summary of Participant Demographic Information ............................... 15

2. Number of Participants Randomly Assigned to Each Condition ...................... 16

3. Descriptive Statistics for Crowne-Marlow Social Desirability Scale Based on Vignette .... 17

4. Descriptive Statistics for Crowne-Marlow Social Desirability Scale Based on Gender ......17

5. Descriptive Statistics for Bem's Sex Role Inventory $\ldots \ldots \ldots \ldots \ldots \ldots \ldots \ldots \ldots \ldots \ldots \ldots \ldots$

6. Results of t-test and Descriptive Statistics for Participant BSRI Group and PD Score ....... 19

7. Results of t-test and Descriptive Statistics for Participant Sex and PD Score .............. 19

8. Results of t-test and Descriptive Statistics for Civilian vs. Veteran Vignettes on PD

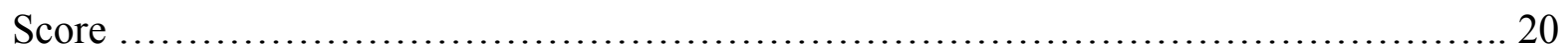

9. Results of t-test and Descriptive Statistics for Male vs. Female Veterans on PD Items ...... 21

10. Results of t-test and Descriptive Statistics for Male Veteran Favorability on PD Items ..... 21

11. Results of t-test and Descriptive Statistics for Participant Sex and SocD Score ............ 22

12. Results of t-test and Descriptive Statistics for Participant BSRI Group and SocD Score .... 22

13. Results of t-test and Descriptive Statistics for Vignette Sex and SocD Score .............. 23

14. Results of t-test and Descriptive Statistics for Veteran vs. Civilian Vignette on SocD

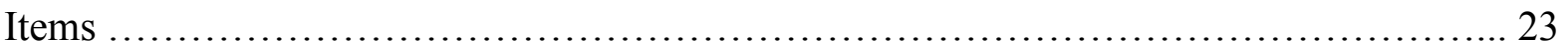

15. Results of t-test and Descriptive Statistics for Male Veteran Favorability on SocD Items ... 24 


\section{LIST OF FIGURES}

$\begin{array}{lll}\text { Figure } & \text { Page }\end{array}$

1. Density Plot of Bem's Sex Role Inventory Scores ................................. 18 



\section{INTRODUCTION}

Post Traumatic Stress Disorder (PTSD) effects approximately $8.7 \%$ of the United States population (American Psychiatric Association, 2013). PTSD is more common among veterans of war than the general population (American Psychiatric Association, 2013). It is estimated that the lifetime prevalence rate of PTSD within the civilian female population is $9.7 \%$ while the lifetime prevalence rate of PTSD in the civilian male population is 3.6\% (Galea et al., 2012). Estimates of lifetime prevalence rates of Vietnam War veterans with PTSD range from 30.9\% for male veterans, and 26.9\% for female veterans (Kang, Natelson, Mahan, Lee, \& Murphy, 2003). Despite the number of veterans suffering from PTSD, only $30 \%$ of veterans with PTSD seek treatment from the VA system (Tanielian, \& Jaycox, 2011).

PTSD has been associated with poorer health outcomes in both males and females. PTSD has also been associated with an overall poorer quality of life (Howgego et al., 2005). Exposure to traumatic events in childhood have been linked to cancer, stroke, heart disease, and lung disease (Felitti et al., 1998). PTSD symptoms have also been linked to an increase in the likelihood of individuals smoking and having issues with alcohol (Schnurr, \& Spiro, 1999). Individuals who suffer from PTSD also have a 60\% greater chance to have marital problems, and are $150 \%$ more likely to be unemployed then those who do not have PTSD (Galovski \& Lyons, 2004). PTSD has been linked to higher rates of suicidality (Hendin \& Haas, 1991). Individuals with PTSD are more likely to be involved with the criminal justice system (Donley et al., 2012). Veterans that suffer from PTSD may have worse health outcomes than individuals with PTSD in the civilian population due to the exposure to debris, pesticides, and other exposures in war zones (Proctor et al., 1998). Recent legislation has also allowed more women to be deployed to 
the front lines, which has the potential to cause more women veterans to develop PTSD in the future.

\section{Stigmatization and Mental Health}

Many individuals suffering from mental illness, such as PTSD, do not seek mental health services (Bebbington, et al., 2000). Stigmatization is one of the barriers that prevents individuals from seeking mental health services. Being diagnosed with a mental illness may lead to individuals stigmatizing themselves because the diagnosis my trigger negative stereotypes the individuals have about the diagnosis they have received (Scheff, 1966).

\section{Public-Stigma}

Stigmatization occurs in multiple forms. One way in which individuals experience stigmatization is through public-stigma (Corrigan \& Watson, 2002). Pubic-stigma occurs when society or a group of individuals perceive another as socially unacceptable, and can be observed through withholding help, avoidance, coercive treatment, and segregated institutions (Corrigan \& Watson, 2002). This can lead to individuals being discriminated against in terms of their ability to obtain employment or housing and may serve as a barrier that prevents them from seeking mental health services (Corrigan, 2004).

\section{Social Distancing}

Individuals may also experience stigmatization through social distancing. Research suggests that many individuals in society attempt to distance themselves from individuals that have been labeled as having a mental illness, or being mentally ill (Link, Phelan, Bresnahan, Stueve, \& Pescosolido, 2002). Individuals may attempt to distance themselves from individuals with mental health problems, because individuals with mental health problems can be perceived as being more responsible for their problems than those suffering from physical issues (Crandall, 
\& Moriarty, 1995; Weiner, Perry, \& Magnusson, 1988). Individuals may try to create this social distance because they view individuals with mental health problems, such as PTSD, with more anger and less pity than individuals suffering from physical health problems (Weiner, Perry, \& Magnusson, 1988).

\section{Self-Stigma}

Individuals with mental health problems may also be stigmatized through self-stigma. Self-stigma refers to an individual's internalization of negative beliefs about the self, an agreement with negative beliefs about themselves, or when an individual labels himself or herself as socially unacceptable (Corrigan \& Watson, 2002; Vogel, Wade, \& Haake, 2006). In order for an individual to experience self-stigma, that individual must be aware of the broader, prevalent stereotypes that exist within that individual's cultural context and agree with those stereotypes (Corrigan, Larson, \& Ruesch, 2009). When an individual internalizes the stigma associated with a particular mental illness, his or her sense of self-esteem and self-efficacy may suffer (Watson, Corrigan, Larson, \& Sells, 2007). Self-efficacy refers to an individual's belief about how much control they have in their ability to influence the events and outcomes in their lives (Bandura, 1994). Self-esteem refers to an individual's conscious reflection on his or her own self-worth (Tafarodi, \& Ho, 2006).

Research indicates that there is a relationship between self-stigma and public-stigma, which may in turn decrease an individual's likelihood to seek psychological services (Vogel, Wade, \& Hackler, 2007). That is, individuals may be less likely to seek mental health services in order to avoid being labeled as mentally ill because they are fearful that it would lower their sense of self-worth, leading to feelings of inferiority and inadequacy (Girma et al., 2013; 
Gulliver, Griffiths, \& Christiansen, 2010; Link, Struening, Neese-Todd, Asmussen, \& Phelan, 2001; Willis, \& DePaulo, 1994).

\section{Gender and Stigma}

Research has also suggested that there are gender differences in perceived stigma associated with mental illness. Males are less likely than females to utilize mental health services (Addis \& Mahalik, 2003). Many men also perceive seeking mental health services as a last resort, and tend to seek out mental health services if they are unable to obtain the support they need through their support systems or social interactions (Angermeyer, Matschinger, \& RiedelHeller, 1999). Traditional male gender roles such as self control, independence, and stoicism, may also contribute to many men feeling like seeking mental health services is a last resort (Addis \& Mahalik, 2003). Research indicates that how a man feels about expressing emotions and affection may also play a role in whether or not he seeks treatment (Good, Dell, \& Mintz, 1989). That is, those men who struggle to express emotion and affection may be less likely to seek mental health services than those who do not (Good, Dell, \& Mintz, 1989).

\section{Gender Role Conflict}

Gender role conflict (GRC), may also play a role in stigmatization. GRC refers to learned societal norms that define rigid, sexist, or restrictive gender roles that in turn lead to a personal restriction or devaluation of self (Good, et al., 1995). GRC may provide a connection between how societal norms script traditional masculine gender roles (i.e., stoicism, assertiveness, power) and whether or not men adopt those roles in their lives (Thompson, Pleck,

\& Ferrera, 1992). The rigidity to which an individual conforms to these roles may produce more interpersonal conflict in his life because how he behaves may not fit the societal script that 
dictates how he should behave or feel (Brooks, \& Silverstein, 1995; Hayes, \& Mahalik, 2000, Mahalik et al., 2003).

However, research also suggests that many males and females do not fit into binary categories of gender (Bem, 1977). Bem (1977) suggests that many males and females have both masculine and feminine traits. It should be noted that individuals who scored in the "masculine" sex role endorse masculine attributes, but reject the feminine attributes, and visa versa (Bem, 1977). Individuals who had an equal number of masculine and feminine traits were labeled “androgynous" (Bem, 1977). The level to which an individual subscribed to their gender role may impact the level to which they stigmatize mental illness.

\section{Gender and PTSD}

Research indicates that women are twice as likely as men to suffer from PTSD in their lifetime (Breslau, 2001; Kessler, Sonnega, Bromet, Hughes, \& Nelson, 1995; Olff, Langelan, Draijer, \& Gersons, 2002). Women are more likely to experience PTSD despite the fact that they are less likely than males to experiences potentially traumatic events (Breslau, 2001, 2009; Tolin, \& Foa, 2006). Women may be more likely to suffer from PTSD due to the severity of the potentially traumatic events they experience, such as childhood sexual assault, and rape (Kessler, Sonnega, Bromet, Hughes, \& Nelson, 1995; Olff, Langelan, Draijer, \& Gersons, 2002; Ullman, \& Filipas, 2005). Research suggests that women are at a much higher risk of developing PTSD than men after experiencing a violent assault, and about one out of every five female veterans suffers from PTSD related to a military sexual trauma (Breslau, 2009; Suris, \& Lind, 2008). Males on the other hand, are more likely to be exposed to potentially traumatic events such as a life threatening illness (Goodman, Corcoran, Turner, Yuan, \& Green, 1998). 
Despite women being diagnosed more frequently than men with PTSD, historically PTSD has been associated with male soldiers who have combat experience (Scott, 1990). However, women are more likely to be diagnosed with PTSD following combat exposure than men (Luxton, Skopp, \& Maguen, 2010). This may be due to women veterans being more likely than male veterans to report having PTSD (Lapierre, Schwegler, \& Labauve, 2007).

\section{Stigma and PTSD}

Mittal et al., found that the public tended to stigmatize veterans with PTSD by labeling them as "dangerous or violent, as well as "crazy." This research also suggests that veterans believed that the public would find them responsible for their own mental illness because they volunteered for military duty (Mittal et al., 2007). This finding was consistent with previous research that addressed stigma surrounding mental illness (Crisp, Gelder, Meltzer, \& Rowland, 2010). Active duty service members may also view other service members who seek mental health services as weak (Hoge et al., 2004). How soldiers view individuals who seek treatment may play a bigger role in whether or not they seek treatment than how they think that others might view them (Britt, Jennings, Cheung, Pury, \& Zinzow, 2015). Research also suggests that soldiers who are diagnosed with mental illness are twice as likely as those soldiers who are not diagnosed with a mental illness to report being concerned with stigma as a barrier to care (Hoge et al., 2004). Soldiers are also more likely to feel embarrassed or fear that they are going to be perceived as weak if they are diagnosed with a mental illness (Mittal et al., 2013).

\section{Stigma, Gender and PTSD}

Currently, there is limited research specifically addressing the differences in perceived stigma surrounding males and females with PTSD. Mendelsohn and Sewell (2004) conducted a study that addressed social attitudes towards gendered responses to trauma. This study found that 
male victims were evaluated less favorably than female victims (Mendelsohn \& Sewell, 2004). This finding supported previous research that has suggested that males are generally rated less favorably than females (Corrigan, Markowitz, Watson, Rowan, \& Kubiak, 2003; Daoud, 2009; Snyder \& Berscheid, 1977). Mendelsohn and Sewell (2004) also reported that women responded more favorably than men towards all victims, and those individuals who were rated as femininesex-typed rated victims more favorably than participants who were rated as being masculine-sextyped. This study also suggests that males who have been trauma victims themselves tend to rate other trauma victims more favorably. Mendelsohn and Sewell (2004) argued that their study suggested that being a trauma victim was more inconsistent with male gender role stereotype than it was with the female gender role stereotype.

Daoud (2009) compared the stigmatization of male and female Iraq War veterans with mental illness to male and female veterans with back pain. This study found support for the idea that veterans with mental illness, such as PTSD or depression, were more stigmatized than veterans with a physical illness such as back pain (Daoud, 2009). This research also suggested that male veterans were perceived as more dangerous than female veterans (Daoud, 2009). Daoud (2009) also suggested that females rated veterans more favorably than male participants.

\section{Summary}

Research indicates that Post Traumatic Stress Disorder (PTSD) is detrimental to both males and female veterans and civilians. Research also indicates that individuals diagnosed with PTSD may not seek services due to self-stigma, public-stigma, and social distancing (Corrigan \& Watson, 2002; Girma et al., 2013; Gulliver et al., 2010; Link et al., 2002; Vogel et al., 2006; Weiner et al., 1988). Previous research has also indicated that there are gender differences within the amount of stigma mental health patients face. In general, research suggests that males are 
more stigmatized than females and less likely to seek treatment (Addis \& Mahalik, 2003; Good, et al., 1995). Women are also more likely to be diagnosed with PTSD than men, and veterans are more likely to be diagnosed with PTSD than civilians (Breslau, 2001; Kessler et al., 1995; Olff et al., 2002). Although women are diagnosed with PTSD more frequently than men, research indicates that male veterans are the most stigmatized (Daoud, 2009; Mittal et al., 2007).

Based on the current body of research, it is still unclear how the level to which an individual subscribes to their gender role affects how they perceive individuals with PTSD. There has also been limited research completed directly comparing civilians and veterans with PTSD, and even less research addressing the stigma surrounding both of those populations.

\section{Purpose}

The purpose of this study is to assess the amount of stigmatization faced by male and female veterans and civilians who suffer from PTSD. This study will help address ways in which stigma can pose as a barrier to individuals suffering from PTSD from seeking mental health services, as well as providing insight into how a participant's gender and sex affect the level of stigma he or she places on an individual with PTSD.

\section{Hypotheses}

Hypothesis 1. Veterans with PTSD will be more stigmatized than civilians with PTSD. This hypothesis is based on previous research that suggests that the public is more likely to view veterans as responsible for their mental illness, and to perceive them as more dangerous or crazy (Mendelsohn \& Sewell, 2004; Mittal et al., 2007).

Hypothesis 2. Males with PTSD will be more stigmatized than females with PTSD. This prediction is based on previous research that has suggested that males with psychiatric disorders are more stigmatized than females who suffer from psychiatric disorders (Schnittker, 2000). This 
hypothesis is also based on past research that suggests that overall males are generally rated less favorably than females (Corrigan et al., 2003; Daoud, 2009; Snyder \& Berscheid, 1977).

Hypothesis 3. Participants who score highly in terms of masculinity on the Bem's SexRole Inventory (BSRI), will rate males with PTSD less favorably than females with PTSD. This hypothesis is based on previous research that has reported that the more rigidly an individual ascribes to the traditional male gender role, the less likely they are to think that a male who has been traumatized, and diagnosed with PTSD is to fit into that traditional male gender role (Brooks, \& Silverstein, 1995; Mendelson, \& Sewell, 2004).

Hypothesis 4. Female participants will rate individuals with PTSD more favorably than male participants. This prediction is based on previous research that has suggested that females are more sympathetic to individuals with mental illness than males (Farina et al., 1973).

Hypothesis 5 . The vignette depicting the male veteran will be rated the least favorably compared to the other vignettes. This prediction is based on previous research that suggests that males are generally viewed more negatively than females (Corrigan et al., 2003; Daoud, 2009; Schnittker, 2000; Snyder \& Berscheid, 1977), as well as research that suggests that veterans with mental illness are viewed with more stigma than civilians with mental illness (Mendelsohn \& Sewell, 2004; Mittal et al., 2007). 


\section{Method}

\section{Participants}

After the study gained approval from the institutional review board (IRB) at California Polytechnic State University San Luis Obispo (Cal Poly), the researcher posted the study onto the Cal Poly Sona website in order to survey undergraduate students enrolled in an undergraduate psychology course. The study obtained a convenience sample of 69 undergraduate students. Five participants were excluded from the study. One participant was excluded because the participant did not agree to the informed consent, and four other participants were excluded because they did not complete the survey. After dropping the five participants, the actual sample size used in the data analyses was $\mathrm{N}=64$.

The sample was made up of 43 females, and 21 male students. The average age of the participants was 18.3 years old $(\mathrm{SD}=0.78)$ with ages ranging from 17 to 22 years old. The sample included participants who identified with a variety of different ethnic backgrounds. Sixty-five percent of the participants identified as white $(n=42), 14$ percent identified as Asian or Pacific Islander $(n=9), 14$ percent identified as mixed race $(n=9)$, and $6.25 \%(n=4)$ identified as Hispanic.

\section{Design}

In order to test the hypotheses the study will have a $2 \times 2$ between subjects quasiexperimental design. The first independent variable of the study will be gender (male or female) affected by PTSD, and the second independent variable of the study will be military experience (veteran or civilian). The dependent variable will be stigmatization. Stigmatization was operationalized in terms of the perceived dangerousness, and social distancing scales. 


\section{Measures}

Demographic information was obtained through a questionnaire at the end of the study. (Appendix F). Participants were asked to select their gender, ethnicity, year in school, and veteran status. Participants were also asked if they had received mental health services, or they had ever received a diagnosis of a mental illness. Participants were also asked if a family member had ever received a mental health diagnosis, or sought treatment from a mental health professional.

Crowne-Marlowe Social Desirability Scale (CMSDS). (Appendix A). This self-report measure contains 33 true or false questions that were designed to measure a participant's tendency to respond in a socially desirable way (Crowne \& Marlowe, 1960). High scores represent the participant's underreporting of information that may be deemed as socially undesirable, or unacceptable, while low scores on this measure may suggest that the participant more willingly reports information that may be socially construed as undesirable (Crowne \& Marlow, 1960). Participants who score between zero and eight on the CMSDS are considered to have a low score, participants who score within the range of nine to 19 are considered to have an average score, while participants who score within the range of 20 to 33 are considered to have high scores (Crowne \& Marlow, 1960). This measure will be used to determine whether or not there is a relationship between participants scores on this measure and the amount of stigma they report upon reviewing the vignette. The CMSDS has an internal consistency with Cronbach's alpha ranging from .73-.88 (Crowne \& Marlow, 1960)

Bem Sex-Role Inventory (BSRI). (Appendix B). The BSRI asks participants to score 60 items on a 7-point Likert scale with "1" being "never, or almost never true" and "7" being “always or almost always true" (Bem,1977). The masculinity and femininity scores from the 
BSRI report the extent to which the participant endorses those personality traits, and is determined from the mean of the scores for the masculine and feminine items (Bem, 1977). Androgyny scores are determined by the difference between the participant's masculinity and femininity scores that have been normalized by the standard deviation ( $t$ ratio) (Bem, 1977). Participant's scores on the BSRI will be used to categorize participants into three categories: masculine, feminine, androgynous. Separating the participants into these categories will allow the researcher to analyze the impact BSRI scores have on the participants levels or reported stigma. The BSRI has proved to have high test-retest reliability (Masculinity $r=0.90$; Femininity $r=0.90$; Androgyny $r=0.93)(B e m, 1977)$. Research also suggests that the BSRI is still a valid measure for assessing gender role perceptions (Holt \& Ellis 1998).

High positive scores on the BSRI represent individuals who endorse feminine personality traits; negative scores represent individuals who represent individuals who endorse masculine personality traits. For the purposes of this study the "most feminine" participants were defined as those participants who had scored higher than 2.025 on the BSRI, as defined by Bem (1977). Masculine participants were defined as individuals who scored below a -2.025 on the BSRI. Androgyny scores are determined by the difference between the participant's masculinity and femininity scores that have been normalized by the standard deviation ( $t$ ratio) (Bem, 1977).

Vignettes. (Appendix C). Four vignettes will be used in this study. The vignettes were developed using the current DSM-5 diagnostic criteria for PTSD in order to establish that the individuals describe in the vignettes met the diagnostic criteria for PTSD. The vignettes were constructed to be as similar as possible in terms of the number of symptoms, exposure to trauma, and the duration the individual had been experiencing symptoms. The vignettes were also constructed to have similar word lengths, and reading difficulty in order to ensure as much 
consistency as possible between groups. The vignettes were tested for internal validity by having five licensed clinical psychologists evaluate whether or not each vignette met each DSM-5 diagnostic criteria for a diagnosis of PTSD.

Social Distance. (Appendix D). Stigmatization can be measured by social distance. Link, Cullen, Frank, \& Wozniak (1987) measured social distance through a seven question surveys that were rated on a 4-point Likert scale where 3 was, "definitely unwilling" and 0 was “definitely willing.” Daound (2009) also used Link et al. (1987) measure to rate social distance. This measure addressed the participants' willingness to interact with the individual described in the vignette across different social situations. Link et al. (1987) had an internal consistency reliability (Cronbach's Alpha) of 0.92 while Daound (2009) had an internal consistency reliability of 0.85 .

Perceived Dangerousness. (Appendix E). Stigmatization can also be measured in terms of perceived dangerousness. Perceived dangerousness may be one of the causal factors of individuals creating social distance from those they stigmatize (Link et al. 1987). Link et al. (1987), Link et al. (1999) and Daoud (2009) all have previously used perceived dangerousness as a way to measure stigmatization. Perceived dangerousness was measured on a 4-point Likert scale with "0" representing "definitely willing" and "3" representing "definitely unwilling." Participants who score lower on the items report more stigma than those with high scores. The internal consistency of the perceived dangerousness scale was has a Cronbach's Alpha score of 0.85 (Link et al. 1987).

\section{Procedure}

The researcher gained approval through the university to place the study online through the university website so that the participants could more readily access the study. Before 
beginning the experiment, participants read through and signed the informed consent form (Appendix G). The informed consent ensured that the participants' data would remain confidential and anonymous. The informed consent also described the general purpose of the study, and informed the participants that their participation in the study was voluntary, and they could stop at anytime should they choose to do so. The participants were also informed that they would not be penalized in anyway should they choose to stop taking part in the study. There were no anticipated risks or discomforts associated with completing the study. Each participant was asked to complete the measures in the following order.

First, the participants were asked to complete the 33, true or false, item CMSDS. Second, the participants were then asked to complete the BSRI. Third, the participants were randomly assigned to one of the four vignettes: Casey (a male, veteran diagnosed with PTSD), Casey (a male, civilian diagnosed with PTSD), Casey (a female, veteran diagnosed with PTSD), or Casey (a female, civilian diagnosed with PTSD). The name Casey was chosen because it is one of the most common androgynous names in the United States according to the Social Security Administration (Flowers, 2015). Fourth, the participants were asked to complete the social distance measures. Sixth, the participants were asked to complete the perceived dangerousness measures. Fifth, the participants were asked to complete the demographic questionnaire. Finally, the participants viewed a debriefing statement thanking them for completing the study, and were given a more detailed description about the purpose of the study. The debriefing statement also contained the researcher's contact information so that the participants could contact the researcher should they have any follow up questions, or concerns. 


\section{Results}

\section{Descriptive Statistics}

Table 1 describes the participants' demographic information. Table 2 describes the how the participants were randomly assigned to each vignette condition.

Table 1.

Summary of Participant Demographic Information

\begin{tabular}{ll}
\hline Variables & $\mathrm{N}$ \\
\hline Gender & \\
Female & 43 \\
Male & 21 \\
Participant total & $64^{*}$ \\
Ethnicity & \\
White & 42 \\
Mixed Race & 10 \\
Asian & 9 \\
Hispanic & 3 \\
Veterans & 0 \\
\hline Age
\end{tabular}

Age $M=18.3, S D=0.781$

*Two participants were excluded for not agreeing to the informed consent, and three other participants were excluded for not completing portions of the study. 
Table 2.

Number of Participants Randomly Assigned to Each Condition

Status of Individual Described in the

Vignette

Veteran Civilian

\begin{tabular}{llcc}
\hline $\begin{array}{l}\text { Gender of } \\
\text { Vignette }\end{array}$ & $\begin{array}{l}\text { Gender of } \\
\text { Participant }\end{array}$ & $\mathrm{n}$ & $\mathrm{n}$ \\
\hline & & 12 & 13 \\
\hline Female & Female & 5 & 9 \\
& Male & 7 & 11 \\
Male & Female & 5 & 2 \\
& Male & 5 & 35
\end{tabular}

\section{Crowne-Marlow Social Desirability Scale}

Participants were categorized based on their CMSDS scores and a three way ANOVA was used to compare participants self reported stigma in terms of perceived dangerousness. The ANOVA showed that the participants scores on the CMSDS did not have a significant effect on their perceived dangerousness scores $\mathrm{F}(2,60)=.023, \mathrm{p}=0.978$. A three way $A N O V A$ was also used to compare the participants' self-reported social distancing scores. The ANOVA showed that the participants scores on the CMSDS did not have a significant effect on their social distancing scores $\mathrm{F}(2,60)=1.03, \mathrm{p}=0.362$.

Table 3 lists the descriptive statistics for how participants scored on the CMSDS based on the vignette they received. Table 4 describes how male and female participants scored on the CMSDS. 
Table 3.

Descriptive Statistics for Crowne-Marlow Social Desirability Scale Based on Vignette

Status of Individual Described in the

Vignette

Veteran Civilian

\begin{tabular}{lcccc}
\hline $\begin{array}{l}\text { Gender of } \\
\text { Vignette }\end{array}$ & & & & \\
& Mean & S.D & Mean & S.D. \\
\hline Female & 16.88 & 4.65 & 15.00 & 5.35 \\
Male & 14.17 & 6.04 & 16.08 & 2.57 \\
\hline
\end{tabular}

Table 4.

Descriptive Statistics for Crowne-Marlow Social Desirability Scale Based on Participant Gender

Gender of

Participant

\begin{tabular}{lcc}
\hline & Mean & S.D. \\
\hline Female & 15.76 & 4.55 \\
Male & 15.14 & 5.61 \\
\hline Total & & \\
\hline
\end{tabular}

\section{Bem's Sex Role Inventory}

The BSRI was utilized to measure how the participants scored in terms of their sex roles.

Table 5 describes how the participants scored on the BSRI. A density plot of all of the participants' scores on the BSRI can be seen in Figure 1. 
Table 5.

Descriptive Statistics for Bem's Sex Role Inventory

$\underline{\text { Sex Role Identification }}$

\begin{tabular}{llcc}
\multicolumn{1}{c}{ Feminine } & Masculine & Androgynous & \\
\hline $\begin{array}{l}\text { Gender of } \\
\text { Participant }\end{array}$ & $\mathrm{n}$ & $\mathrm{n}$ & $\mathrm{n}$ \\
\hline & 0 & 33 & 10 \\
\hline Female & 0 & 20 & 1 \\
Male & & & 11 \\
\hline Total & 0 & 53 & \\
\hline
\end{tabular}

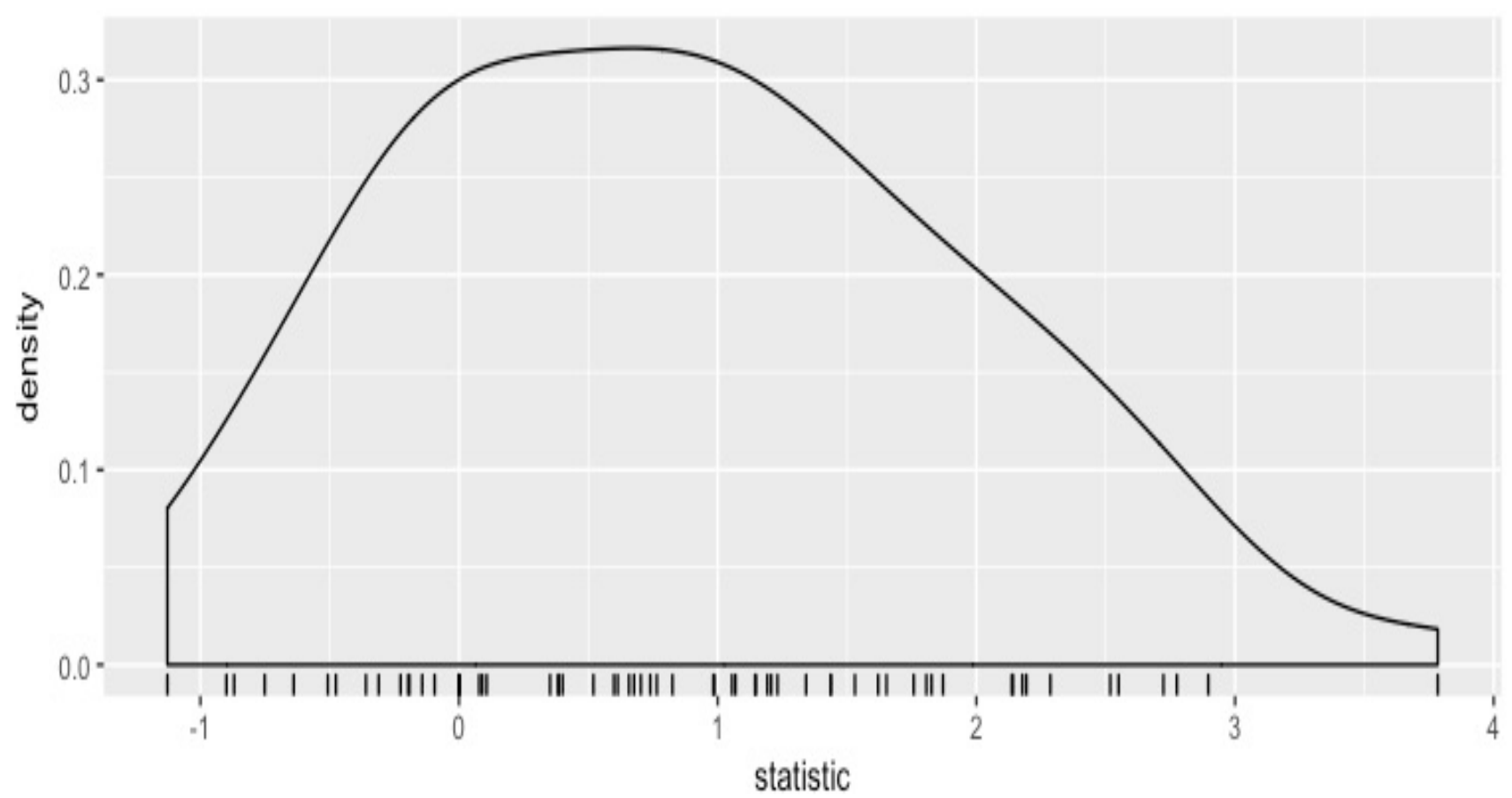

Figure 1. Density Plot of Bem's Sex Role Inventory Scores 


\section{Perceived Dangerousness (PD)}

A Welch's two-sample t-test was used to compare the most feminine participants to other participants in the study. The test did not find a significant difference in how the most feminine participants scored $(\mathrm{M}=2.01, \mathrm{SD}=0.520)$ on the perceived dangerousness measures as compared to the other participants $(\mathrm{M}=2.07, \mathrm{SD}=0.528) t(15)=-0.32, p=0.756$, as described in Table 6.

Table 6.

Results of t-test and Descriptive Statistics for Participant BSRI Group and PD Score

\begin{tabular}{|c|c|c|c|c|c|c|}
\hline & \multicolumn{4}{|c|}{ BSRI Group } & \multicolumn{2}{|c|}{$\begin{array}{l}95 \% \text { CI for } \\
\text { Mean Difference }\end{array}$} \\
\hline & \multicolumn{2}{|c|}{ Androgynous } & \multicolumn{2}{|c|}{ Feminine } & & \\
\hline $\mathrm{df}$ & M & SD & M & SD & & $\mathrm{t}$ \\
\hline $\begin{array}{r}\text { PD Score } \\
15\end{array}$ & 2.07 & 0.528 & 2.01 & 0.520 & $-0.424,0.314$ & -0.32 \\
\hline
\end{tabular}

A Welch's t-test was also used to compare how male and female participants scored on the perceived dangerousness measures. The test did not find a significant difference between how male participants $(\mathrm{M}=1.94, \mathrm{SD}=0.540)$ and female participants $(\mathrm{M}=2.13, \mathrm{SD}=0.512)$ scored on the perceived dangerousness measures $t(38)=1.22, p=0.229$, as described in Table 7 . Table 7.

Results of t-test and Descriptive Statistics for Participant Sex and PD Score

\begin{tabular}{|c|c|c|c|c|c|c|}
\hline & \multicolumn{3}{|c|}{ Participant Sex } & & \multicolumn{2}{|c|}{$\begin{array}{l}95 \% \text { CI for } \\
\text { Mean Difference }\end{array}$} \\
\hline & Male & & Fema & & & \\
\hline $\mathrm{df}$ & $\mathrm{M}$ & $\mathrm{SD}$ & $\mathrm{M}$ & $\mathrm{SD}$ & & $\mathrm{t}$ \\
\hline $\begin{array}{r}\text { PD Score } \\
38\end{array}$ & 1.94 & 0.540 & 2.13 & 0.512 & $-0.113,0.459$ & 1.22 \\
\hline
\end{tabular}


A Welch's two-sample t-test was used to compare how the participants who received the veteran vignettes scored on the perceived dangerousness measures as compared to the civilian vignettes. The test determined that there was not a significant difference between the perceived dangerousness scores on the veteran vignettes $(\mathrm{M}=2.15, \mathrm{SD}=0.59)$ and the civilian vignettes $(\mathrm{M}=1.28, \mathrm{SD}=0.45) t(52)=-1.23 p=0.226$ as described in Table 8.

Table 8 .

Results of t-test and Descriptive Statistics for Civilian vs. Veteran Vignette on PD Items

\begin{tabular}{|c|c|c|c|c|c|c|}
\hline & \multicolumn{4}{|c|}{ Status of Vignette } & \multicolumn{2}{|c|}{$\begin{array}{l}95 \% \text { CI for } \\
\text { Mean Difference }\end{array}$} \\
\hline & \multicolumn{2}{|c|}{ Veteran } & \multicolumn{2}{|c|}{ Civilian } & & \\
\hline $\mathrm{df}$ & $\mathrm{M}$ & $\mathrm{SD}$ & $\mathrm{M}$ & $\mathrm{SD}$ & & $\mathrm{t}$ \\
\hline $\begin{array}{r}\text { PD Score } \\
52\end{array}$ & 2.15 & 0.59 & 1.28 & 0.45 & $-0.434,0.105$ & -1.23 \\
\hline
\end{tabular}

Perceived dangerousness scores were also compared in terms of the sex of the veteran presented in the vignette. A Welch's two-sample t-test was used to compare how the participants who received the female veteran vignettes scored on the perceived dangerousness items compared to the participants who received the male veteran vignettes. The test determined that there was not a significant difference between the perceived dangerousness scores on the male vignettes $(M=2.17, S D=0.506)$ and the female vignettes $(M=1.99, S D=0.529) t(53)=-1.35$, $p=0.184$, as described in Table 9. 
Table 9.

Results of t-test and Descriptive Statistics for Male vs. Female Veterans on PD Items

\begin{tabular}{|c|c|c|c|c|c|c|}
\hline & & Veteran Sex & & & $\begin{array}{l}95 \% \text { CI for } \\
\text { Mean Difference }\end{array}$ & \\
\hline & Male & & Fema & & & \\
\hline df & $\bar{M}$ & SD & $\mathrm{M}$ & SD & & $\bar{t}$ \\
\hline $\begin{array}{r}\text { PD Score } \\
53\end{array}$ & 2.17 & 0.506 & 1.99 & 0.529 & $-0.442,0.0868$ & -1.35 \\
\hline
\end{tabular}

A Welch's two-sample t-test was used to compare how the participants who received the male veteran vignette scored on the perceived dangerousness items as compared to participants who received all of the other vignette conditions. The test determined that individuals who received the male veteran vignette $(\mathrm{M}=2.33, \mathrm{SD}=0.447)$ scored significantly higher than those who received all other vignettes $(\mathrm{M}=1.99, \mathrm{SD}=0.522) t(19)=-2.30, p=0.033$, as described in Table 10.

Table 10.

Results of t-test and Descriptive Statistics for Male Veteran Favorability on PD Items

\begin{tabular}{|c|c|c|c|c|c|c|}
\hline & & Veteran Sex & & & $\begin{array}{l}95 \% \text { CI for } \\
\text { Mean Difference }\end{array}$ & \\
\hline & Male & & Femal & & & \\
\hline $\mathrm{df}$ & $\mathrm{M}$ & $\mathrm{SD}$ & $\mathrm{M}$ & SD & & $\mathrm{t}$ \\
\hline $\begin{array}{r}\text { PD Score } \\
19\end{array}$ & 2.33 & 0.447 & 1.99 & 0.522 & $-0.651,-0.030$ & -2.30 \\
\hline
\end{tabular}

Social Distancing (SocD)

A Welch's two-sample t-test was used to compare how male and female participants scored in terms of the social distancing items. The test determined that male participants scored significantly higher on the social distancing measures $(\mathrm{M}=3.24, \mathrm{SD}=0.516)$ as compared to female participants $(\mathrm{M}=2.94, \mathrm{SD}=0.536) t(41)=-2.14, p=0.038$, as described in Table 11 . 
Table 11.

Results of t-test and Descriptive Statistics for Participant Sex and SocD Score

\begin{tabular}{|c|c|c|c|c|c|c|}
\hline & & Partici & & & $95 \%$ CI for & \\
\hline & Male & & Fem & & & \\
\hline & $\mathrm{M}$ & $\mathrm{SD}$ & $\mathrm{M}$ & SD & & $\mathrm{t}$ \\
\hline$\frac{\mathrm{df}}{\text { SocD Score }}$ & 3.24 & 0.516 & 2.94 & 0.536 & $-0.579,-0.017$ & -2.14 \\
\hline
\end{tabular}

A Welch's two-sample t-test was used to compare individuals that scored most feminine on the BSRI to the rest of the participants. The test determined that there was not a significant difference between the most feminine participants $(\mathrm{M}=2.96, \mathrm{SD}=0.636)$ and the rest of the participants $(\mathrm{M}=3.05, \mathrm{SD}=0.528) t(14)=-0.45, p=0.658$, as described in Table 12. Table 12.

Results of t-test and Descriptive Statistics for Participant BSRI Group and SocD Score

\begin{tabular}{|c|c|c|c|c|c|c|}
\hline & & BSRI Group & & & $\begin{array}{l}95 \% \text { CI for } \\
\text { Mean Difference }\end{array}$ & \\
\hline & Andr & gynous & Femi & & & \\
\hline $\mathrm{df}$ & $\mathrm{M}$ & SD & $\mathrm{M}$ & SD & & $\overline{\mathrm{t}}$ \\
\hline $\begin{array}{c}\text { SocD Score } \\
14\end{array}$ & 3.05 & 0.528 & 2.96 & 0.636 & $-0.536,0.350$ & -0.45 \\
\hline
\end{tabular}

Welch's two-sample t-test was also used to compare scores on social distancing measures across the sex of the individuals described in the vignettes. The test determined that there was not a significant difference between how the participants who received the female vignettes scored on the social distancing measures $(\mathrm{M}=3.10, \mathrm{SD}=0.561)$ as compared to the individuals who received the male vignettes $(\mathrm{M}=2.94, \mathrm{SD}=0.512) t(55)=1.15, p=0.257$, as described in Table 13. 
Table 13.

Results of t-test and Descriptive Statistics for Vignette Sex and SocD Scores

\begin{tabular}{|c|c|c|c|c|c|}
\hline & & Vignette Sex & & $\begin{array}{l}95 \% \text { CI for } \\
\text { Mean Difference }\end{array}$ & \\
\hline & Male & & Female & & \\
\hline $\mathrm{df}$ & $\mathrm{M}$ & $\mathrm{SD}$ & $\begin{array}{ll}\mathrm{M} & \mathrm{SD}\end{array}$ & & $\overline{\mathrm{t}}$ \\
\hline $\begin{array}{c}\text { SocD Score } \\
55\end{array}$ & 2.94 & 0.512 & $3.10 \quad 0.561$ & $-0.117,0.429$ & 1.15 \\
\hline
\end{tabular}

A Welch's two-sample t-test was used to compare how the participants who received the veteran vignettes scored on the social distancing measures as compared to the civilian vignettes. The test determined that there was not a significant difference between the social distancing scores on the veteran vignettes $(\mathrm{M}=2.93, \mathrm{SD}=0.546)$ and the civilian vignettes $(\mathrm{M}=3.13, \mathrm{SD}$ $=0.533) t(59)=1.44 p=0.155$, as described in Table 14 .

Table 14.

Results of t-test and Descriptive Statistics for Veteran vs. Civilian Vignettes on SocD Items $\begin{array}{ll}\text { Status of Vignette } & 95 \% \text { CI for } \\ & \text { Mean Difference }\end{array}$

\begin{tabular}{cllllll}
\hline \multicolumn{5}{c}{ Veteran } & \multicolumn{4}{l}{ Civilian } & \\
\hline df & M & SD & M & SD & & t \\
\hline $\begin{array}{c}\text { SocD Score } \\
59\end{array}$ & 2.93 & 0.546 & 3.13 & 0.533 & $-0.076,0.467$ & 1.44 \\
\hline$p=0.155$ & & & & & & \\
\hline
\end{tabular}

A Welch's two-sample t-test was used to compare how the participants who received the male veteran vignette scored on the social distancing items as compared to participants who received all of the other vignette conditions. The test determined that there were no statistically significant differences in how individuals who received the male veteran vignette $(\mathrm{M}=2.88, \mathrm{SD}$ $=0.490)$ scored as compared to those who received all other vignettes $(\mathrm{M}=3.07, \mathrm{SD}=0.553)$ $t(18)=1.20, p=0.246$, as described in Table 15. 
Table 15 .

Results of t-test and Descriptive Statistics for Male Veteran Favorability on SocD Items

\begin{tabular}{|c|c|c|c|c|c|c|}
\hline & & Veteran Sex & & & $\begin{array}{l}95 \% \text { CI for } \\
\text { Mean Difference }\end{array}$ & \\
\hline & Male & & Fems & & & \\
\hline $\mathrm{df}$ & $\mathrm{M}$ & $\mathrm{SD}$ & $\mathrm{M}$ & $\mathrm{SD}$ & & $\mathrm{t}$ \\
\hline $\begin{array}{r}\text { PD Score } \\
18\end{array}$ & 2.88 & 0.490 & 3.07 & 0.553 & $-0.145,0.531$ & 1.20 \\
\hline
\end{tabular}

\section{Discussion}

\section{Summary of Findings}

The current study examined the impact gender, and veteran status placed on the degree of perceived stigmatization individuals with a PTSD diagnosis face using a self-report survey questionnaire. Stigma was operationally defined as the level of perceived dangerousness the participant reported, and the amount of social distance the participants reported wanting from the individuals described in the vignettes. The results with regard to each hypothesis will be reviewed, and stigmatization will be discussed in general.

Due to a lack of statistical significance, and power the current study was unable to group the participants into three distinct groups (Masculine, Feminine, Androgynous) with regards to their scores on the BSRI. Instead, the participants were categorized as either androgynous or feminine.

Hypothesis 1. Veterans with PTSD will be more stigmatized than civilians with PTSD. This hypothesis was based on previous research that suggests that the public is more likely to view veterans as responsible for their mental illness, and to perceive them as more dangerous or crazy (Mendelsohn \& Sewell, 2004; Mittal et al., 2007). The current study did not find support for this hypothesis, and there were no statistically significant differences between how 
individuals who received the veteran vignettes scored on both the perceived dangerousness, and social distancing measures. However, these results did support previous research as described by Daoud, (2009) who also did not find significant differences between how participants stigmatized veterans and civilians with PTSD. A possible explanation for this finding is that there has been very limited research that has directly compared veterans and civilians with a PTSD diagnoses, and have instead focused on broader community samples. An additional possible explanation for this finding could be explained in terms of the participants' ambivalence towards members of the military and mental health problems. For example an individual may hold positive views towards veterans, and military members for their service, but at the same time hold negative beliefs about mental health. The ambivalence between these two factors may impact the participants' the level of reported stigma.

Hypothesis 2. Males with PTSD will be more stigmatized than females with PTSD. This prediction was based on previous research that has suggested that males with psychiatric disorders are more stigmatized than females who suffer from psychiatric disorders (Schnittker, 2000), and that overall males are generally rated less favorably than females (Corrigan et al., 2003; Snyder \& Berscheid, 1977). The results of the current study did not find support for this hypothesis. There was not a statistically significant difference between how the participants rated the male vignettes, and the female vignettes. This finding could be explained by sampling errors. Participants in this study may have reported no significant differences in stigma across genders of the individuals depicted in the vignettes because through their coursework they have been exposed to, and educated about individuals with mental health problems. Research suggests that students with more exposure to mental health issues are less likely to hold negative attitudes towards individuals with mental health problem (Chung, Chen, \& Liu, 2001). 
Hypothesis 3. Participants who score highly in terms of masculinity on the Bem's SexRole Inventory (BSRI), will rate males with PTSD less favorably than females with PTSD. This hypothesis was based on previous research that has reported that the more rigidly an individual ascribes to the traditional male gender role, the less likely they are to think that a male who has been traumatized, and diagnosed with PTSD is to fit into that traditional male gender role (Brooks, \& Silverstein, 1995; Mendelson, \& Sewell, 2004). The current study was unable to fully test hypothesis 3 because there was an insufficient number of participants who scored within the masculine range on the BSRI. The current study's inability to obtain a large enough sample of masculine participants was likely due to sampling problems. The current study was only able to sample from a small pool of participants, from an introductory level psychology course, which could explain why the individuals sampled in this study held fewer of the stereotypically masculine personality traits.

However, there were a significant amount of participants who scored as feminine as defined by Bem (1977). The cut off for individuals to be in this range was a score of greater than or equal to 2.025 (Bem, 1977). For the purposes of this study, the most feminine participants were compared to all other participants and there were no statistically significant differences between how the most feminine participants scored on the social distancing and perceived dangerousness measures. These findings may suggest that despite there were not large enough differences in terms of personality traits between the most feminine participants, and the other participants in the study.

Hypothesis 4. Female participants will rate individuals with PTSD more favorably than male participants. This prediction was based on previous research that suggested females are more sympathetic to individuals with mental illness than males (Farina et al., 1973). This 
hypothesis was supported by the results of this study. Male participants scored significantly higher on the social distancing measures than female participants. In other words, male participants wanted to distance themselves more from individuals with PTSD than female participants. This finding may be explained in terms of GRC. Stereotypically in our society, females are responsible for being nurturing and tending to individuals needs, while stereotypically males are supposed to be tough and stoic. It is possible that the males in this study reported wanting more social distance from the individuals depicted in the vignettes because doing so would align with their prescribed gender roles, and would therefore not negatively impact their GRC.

Hypothesis 5 . The vignette depicting the male veteran will be rated the least favorably compared to the other vignettes. This prediction is based on previous research that suggests that males are generally viewed more negatively than females (Corrigan et al., 2003; Schnittker, 2000; Snyder \& Berscheid, 1977), as well as research that suggests that veterans with mental illness are viewed with more stigma than civilians with mental illness (Mendelsohn \& Sewell, 2004; Mittal et al., 2007). The current study found mix results with respect to whether or not the vignette depicting the male veteran would be rated as having the most stigma. Participants who received the male veteran vignette scored significantly higher on the perceived dangerousness measures, but not the social distancing measures as compared to the other vignette conditions. These findings may be explained by the idea that males are often depicted as being more physically dangerous than females in our society. The portrayal of men as being more dangerous also aligns closely with the stereotypically masculine gender role. Participants may have felt that the male veterans were more dangerous than the female veterans due to the sociocultural and systemic lens they were viewing them through. However, the participants may not have reported 
wanting greater social distance from the individual depicted in the male veteran vignette because the participants may have habituated to seeing males as more dangerous than females.

\section{Limitations}

Many of the limitations of this study surround sampling. Due to IRB restraints, the current study was only able to obtain a convince sample of undergraduate students enrolled in the psychology 202 class. It is likely that individuals enrolled in psychology courses hold less stigma than the general population. This idea is influenced by the fact that most college students are exposed to the negative impact stigma and sexism have on individuals lives (Astin, 1993). Research also suggests that as students become exposed to this material, they tend to impart less stigma on others (Lottes \& Kuriloff, 1994). This may explain part of the reason why the participants of this study overall tended not to report stigmatizing the individuals presented in the vignettes.

Another limitation of this study was a lack of statistical power. The current study had a limited number of participants in each condition. The study also had significantly fewer male participants than female participants. The limited number of participants in each condition likely impacted the results of the study because the limited number of participants was likely not representative of the population as a whole. It is possible that with more statistical power, the study could have had gained a clearer view of how gender and veteran status impact the stigma surrounding individuals with PTSD.

Another limitation of the study was that the study did not obtain an ethnically diverse population. Different ethnic and cultural backgrounds may have different views on gender roles, veterans, and mental illness. The current study was also unable to obtain a single veteran to take part in the study. It is possible that military veteran culture influences their views on gender 
differences and civilians or veterans with PTSD. Although the study will attempt to control for some of the limits associated with a self-report survey by addressing the participants' level of social desirability, it is still possible that participant's will not complete the measures truthfully.

\section{Future Research}

Future research could address the limitations of this study in a variety of ways. Future research could attempt to gain a more representative sample of participants. Future studies need to further examine the role stigma plays in preventing individuals with mental illness from seeking services. Future studies should also further examine the different types of stigma that both veterans, and civilians with mental illness face.

It also would be important for future studies to examine how individuals who are involved in the military perceive individuals with PTSD due to the uniqueness of military culture. Future studies could also compare individuals from different branches of the military to determine if certain branches of the military are more stigmatizing than others.

It should also be noted that stigma impacts individuals outside of the populations addressed in this study. Future research needs to address how other factors such as race, sexual orientation, religious affiliation, socioeconomic status and other sociocultural factors impact how individuals are viewed and treated in our society. This research should also address ways to combat stigma and the marginalization of minority groups.

\section{Implications}

This study could have clinical implications by determining barriers for seeking treatment. Individuals who perceive stigma surrounding mental health issues are less likely to seek treatment. It is important to gain a better understanding of how gender and veteran status both impact the stigma surrounding a mental health issue such as PTSD to not only understand the 
barriers that may get in the way of individuals seeking treatment, but also to understand the helpseeking behaviors of the individuals in those groups. Helping individuals understand gender differences may also inform more effective ways to encourage individuals to seek treatment, and address ways to decrease gender-based stigma. This study found support for the idea that males are more likely to be stigmatizing towards individuals with PTSD than females are. Formulating psychoeducation, and campaigns that specifically address males, and the impact of stereotypic masculine roles may be one way to combat this phenomenon. 


\section{References}

American Psychiatric Association. (2013). Diagnostic and statistical manual of mental disorders (5th ed.). Arlington, VA: American Psychiatric Publishing.

Addis, M. E., \& Mahalik, J. R. (2003). Men, masculinity, and the contexts of help seeking. American psychologist, 58(1), 5.

Angermeyer, M. C., Matschinger, H., \& Riedel-Heller, S. G. (1999). Whom to ask for help in case of a mental disorder? Preferences of the lay public. Social psychiatry and psychiatric epidemiology, 34(4), 202-210.

Astin, A. W. (1993). Diversity and multiculturalism on the campus: How are students affected?. Change: The Magazine of Higher Learning, 25(2), 44-49.

Bandura, A. (1994). Self-efficacy. John Wiley \& Sons, Inc..

Bebbington, P. E., Meltzer, H., Brugha,T. S., Farrell, M., Jenkins, R., Ceresa, C., Lewis, G., (2000). Unequal access and unmet need:neurotic disorders and the use of primary care services. Psychological Medicine, 30, 1359-1367.

Bem, S. L. (1977). On the utility of alternative procedures for assessing psychological androgyny. Journal of consulting and clinical psychology, 45(2), 196.

Breslau, N. (2001). Gender differences in trauma and posttraumatic stress disorder. The journal of gender-specific medicine: JGSM: the official journal of the Partnership for Women's Health at Columbia, 5(1), 34-40.

Breslau, N. (2009). The epidemiology of trauma, PTSD, and other posttrauma disorders. Trauma, Violence, \& Abuse.

Brooks, G. R., \& Silverstein, L. B. (1995). Understanding the dark side of masculinity: An interactive systems model.

Britt, T. W., Jennings, K. S., Cheung, J. H., Pury, C. S., \& Zinzow, H. M. (2015). The role of different stigma perceptions in treatment seeking and dropout among active duty military personnel. Psychiatric Rehabilitation Journal, 38(2), 142-149. doi:10.1037/prj0000120

Chung, K. F., Chen, E. Y., \& Liu, C. S. (2001). University students' attitudes towards mental patients and psychiatric treatment. International Journal of Social Psychiatry, 47(2), 6372.

Corrigan, P. (2004). How stigma interferes with mental health care. American psychologist, $59(7), 614$. 
Corrigan, P., Markowitz, F. E., Watson, A., Rowan, D., \& Kubiak, M. A. (2003). An attribution model of public discrimination towards persons with mental illness. Journal of health and Social Behavior, 162-179.

Corrigan, P. W., Larson, J. E., \& Ruesch, N. (2009). Self-stigma and the "why try" effect: impact on life goals and evidence-based practices. World Psychiatry, 8(2), 75-81.

Corrigan, P. W., \& Watson, A. C. (2002). The paradox of self-stigma and mental illness. Clinical Psychology: Science and Practice, 9(1), 35-53.

Crandall, C. S., \& Moriarty, D. (1995). Physical illness stigma and social rejection. British Journal of Social Psychology, 34(1), 67-83.

Crisp, A. H., Gelder, M. G., Rix, S., Meltzer, H. I., \& Rowlands, O. J. (2000). Stigmatisation of people with mental illnesses. The British Journal of Psychiatry, 177(1), 4-7.

Crowne, D. P., \& Marlowe, D. (1960). A new scale of social desirability independent of psychopathology. Journal of consulting psychology, 24(4), 349.

Daoud, M. (2009). Stigmatization of Iraq veterans with PTSD, depression, or chronic back pain.

Donley, S., Habib, L., Jovanovic, T., Kamkwalala, A., Evces, M., Egan, G., ... \& Ressler, K. J. (2012). Civilian PTSD symptoms and risk for involvement in the criminal justice system. Journal of the American Academy of Psychiatry and the Law Online, 40(4), 522-529.

Farina, A., Felner, R. D., \& Boudreau, L. A. (1973). Reactions of workers to male and female mental patient job applicants. Journal of Consulting and Clinical Psychology, 41(3), 363.

Felitti, V. J., Anda, R. F., Nordenberg, D., Williamson, D. F., Spitz, A. M., Edwards, V., ... \& Marks, J. S. (1998). Relationship of childhood abuse and household dysfunction to many of the leading causes of death in adults: The Adverse Childhood Experiences (ACE) Study. American journal of preventive medicine, 14(4), 245-258.

Flowers, Andrew. (2015, June 10). The Most Common Unisex Names in America: Is Yours One Of Them?. FiveThirtyEight. Retireved from

http://fivethirtyeight.com/features/there-are-922-unisex-names-in-america-is-yours-one-of-them/

Galea, S., Basham, K., Culpepper, L., Davidson, J., Foa, E., Kizer, K., ... \& Milad, M. (2012). Treatment for posttraumatic stress disorder in military and veteran populations: Initial assessment. National Academies Press: Washington DC.

Galovski, T., \& Lyons, J. A. (2004). Psychological sequelae of combat violence: A review of the impact of PTSD on the veteran's family and possible interventions. Aggression and violent behavior, 9(5), 477-501.

Girma, E., Tesfaye, M., Froeschl, G., Möller-Leimkühler, A. M., Dehning, S., \& Müller, N. (2013). Facility based cross-sectional study of self stigma among people with mental 
illness: towards patient empowerment approach. International journal of mental health systems, $7(1), 1$.

Good, G. E., Dell, D. M., \& Mintz, L. B. (1989). Male role and gender role conflict: Relations to help seeking in men. Journal of counseling psychology, 36(3), 295.

Good, G. E., Robertson, J. M., O'Neil, J. M., Fitzgerald, L. F., Stevens, M., DeBord, K. A., \& ... Braverman, D. G. (1995). Male gender role conflict: Psychometric issues and relations to psychological distress. Journal Of Counseling Psychology, 42(1), 3-10. doi:10.1037/0022-0167.42.1.3

Goodman, L. A., Corcoran, C., Turner, K., Yuan, N., \& Green, B. L. (1998). Assessing traumatic event exposure: General issues and preliminary findings for the Stressful Life Events Screening Questionnaire. Journal of traumatic stress, 11(3), 521-542.

Gulliver, A., Griffiths, K. M., \& Christensen, H. (2010). Perceived barriers and facilitators to mental health help-seeking in young people: a systematic review. BMC psychiatry, 10(1), 1.

Hayes, J. A., \& Mahalik, J. R. (2000). Gender role conflict and psychological distress in male counseling center clients. Psychology of Men \& Masculinity, l(2), 116.

Hendin, H., \& Haas, A. P. (1991). Suicide and guilt as manifestations of PTSD. American Journal of Psychiatry, 148(5), 586-591.

Hoge, C. W., Castro, C. A., Messer, S. C., McGurk, D., Cotting, D. I., \& Koffman, R. L. (2004). Combat duty in Iraq and Afghanistan, mental health problems, and barriers to care. New England Journal of Medicine, 351(1), 13-22.

Holt, C. L., \& Ellis, J. B. (1998). Assessing the current validity of the Bem Sex-Role Inventory. Sex roles, 39(11), 929-941.

Howgego, I. M., Owen, C., Meldrum, L., Yellowlees, P., Dark, F., \& Parslow, R. (2005). Posttraumatic stress disorder: An exploratory study examining rates of trauma and PTSD and its effect on client outcomes in community mental health. BMC psychiatry, 5(1), 1.

Kang, H. K., Natelson, B. H., Mahan, C. M., Lee, K. Y., \& Murphy, F. M. (2003). Posttraumatic stress disorder and chronic fatigue syndrome-like illness among Gulf War veterans: a population-based survey of 30,000 veterans. American journal of epidemiology, 157(2), 141-148.

Kessler, R. C., Sonnega, A., Bromet, E., Hughes, M., \& Nelson, C. B. (1995). Posttraumatic stress disorder in the National Comorbidity Survey. Archives of general psychiatry, 52(12), 1048-1060. 
Kulka, R. A., Schlenger, W. E., Fairbank, J. A., Hough, R. L., Jordan, B. K., Marmar, C. R., Weiss, D. S. (1988). Contractual Report of Findings from the National Vietnam Veterans' Readjustment Study: Volumes 1-4. North Carolina: Research Triangle Institute.

Lapierre, C. B., Schwegler, A. F., \& LaBauve, B. J. (2007). Posttraumatic stress and depression symptoms in soldiers returning from combat operations in Iraq and Afghanistan. Journal of traumatic stress, 20(6), 933-943.

Link, B. G., Cullen, F. T., Frank, J., \& Wozniak, J. F. (1987). The social rejection of former mental patients: Understanding why labels matter. American journal of Sociology, 14611500 .

Link, B. G., Phelan, J. C., Bresnahan, M., Stueve, A., \& Pescosolido, B. A. (1999). Public conceptions of mental illness: labels, causes, dangerousness, and social distance. American journal of public health, 89(9), 1328-1333.

Link, B. G., Struening, E. L., Neese-Todd, S., Asmussen, S., \& Phelan, J. C. (2001). Stigma as a barrier to recovery: The consequences of stigma for the self-esteem of people with mental illnesses. Psychiatric services.

Lottes, I. L., \& Kuriloff, P. J. (1994). The impact of college experience on political and social attitudes. Sex Roles, 31(1-2), 31-54.

Luxton, D. D., Skopp, N. A., \& Maguen, S. (2010). Gender differences in depression and PTSD symptoms following combat exposure. Depression and anxiety, 27(11), 1027-1033.

Mahalik, J. R., Locke, B. D., Ludlow, L. H., Diemer, M. A., Scott, R. P., Gottfried, M., \& Freitas, G. (2003). Development of the Conformity to Masculine Norms Inventory. Psychology of Men \& Masculinity, 4(1), 3.

Mendelsohn, M., \& Sewell, K. W. (2004). Social attitudes toward traumatized men and women: A vignette study. Journal of traumatic stress, 17(2), 103-111.

Mittal, D., Drummond, K. L., Blevins, D., Curran, G., Corrigan, P., \& Sullivan, G. (2013). Stigma associated with PTSD: perceptions of treatment seeking combat veterans. Psychiatric rehabilitation journal, 36(2), 86.

Olff, M., Langeland, W., Draijer, N., \& Gersons, B. P. (2007). Gender differences in posttraumatic stress disorder. Psychological bulletin, 133(2), 183.

Proctor, S. P., Heeren, T., White, R. F., Wolfe, J., Borgos, M. S., Davis, J. D., ... \& Oznoff, D. (1998). Health status of Persian Gulf War veterans: self-reported symptoms, environmental exposures and the effect of stress. International Journal of Epidemiology, $27(6), 1000-1010$.

Scheff, T. J. (1970). Being mentally ill: A sociological theory. Transaction Publishers. 
Schnittker, J. (2000). Gender and reactions to psychological problems: An examination of social tolerance and perceived dangerousness. Journal of Health and Social Behavior, 224-240.

Schnurr, P. P., \& SPIRO III, A. V. R. O. N. (1999). Combat exposure, posttraumatic stress disorder symptoms, and health behaviors as predictors of self-reported physical health in older veterans. The Journal of nervous and mental disease, 187(6), 353-359.

Scott, W. J. (1990). PTSD in DSM-III: A case in the politics of diagnosis and disease. Social problems, 37(3), 294-310.

Seal, K. H., Metzler, T. J., Gima, K. S., Bertenthal, D., Maguen, S., \& Marmar, C. R. (2009). Trends and risk factors for mental health diagnoses among Iraq and Afghanistan veterans using Department of Veterans Affairs health care, 2002-2008. American journal of public health, 99(9), 1651-1658.

Snyder, M., Tanke, E. D., \& Berscheid, E. (1977). Social perception and interpersonal behavior: On the self-fulfilling nature of social stereotypes. Journal of Personality and Social Psychology, 35(9), 656.

Surís, A., \& Lind, L. (2008). Military sexual trauma a review of prevalence and associated health consequences in veterans. Trauma, Violence, \& Abuse, 9(4), 250-269.

Tafarodi, R. W., \& Ho, C. (2006). Implicit and explicit self-esteem: What are we measuring?. Canadian Psychology/Psychologie Canadienne, 47(3), 195-202. doi:10.1037/cp2006009

Tanielian, T., \& Jaycox, L. H. (2011). The Invisible Wounds of War: Psychological and Cognitive Injuries, Their Consequences, and Services to Assist Recovery (Santa Monica, CA: RAND Corporation, MG-720-CCF, 2008). Post-Traumatic Stress Disorder Among Adults.

Tolin, D. F., \& Foa, E. B. (2006). Sex differences in trauma and posttraumatic stress disorder: a quantitative review of 25 years of research. Psychological bulletin, 132(6), 959.

Thompson, E. H., Pleck, J. H., \& Ferrera, D. L. (1992). Men and masculinities: Scales for masculinity ideology and masculinity-related constructs. Sex roles, 27(11-12), 573-607.

Ullman, S. E., \& Filipas, H. H. (2005). Gender differences in social reactions to abuse disclosures, post-abuse coping, and PTSD of child sexual abuse survivors. Child abuse \& neglect, 29(7), 767-782.

Vogel, D. L., Wade, N. G., \& Haake, S. (2006). Measuring the self-stigma associated with seeking psychological help. Journal of Counseling Psychology, 53(3), 325.

Vogel, D. L., Wade, N. G., \& Hackler, A. H. (2007). Perceived public stigma and the willingness to seek counseling: The mediating roles of self-stigma and attitudes toward counseling. Journal of Counseling Psychology, 54(1), 40. 
Watson, A. C., Corrigan, P., Larson, J. E., \& Sells, M. (2007). Self-stigma in people with mental illness. Schizophrenia bulletin, 33(6), 1312-1318.

Weiner, B., Perry, R. P., \& Magnusson, J. (1988). An attributional analysis of reactions to stigmas. Journal of personality and social psychology, 55(5), 738.

Wills, T. A., \& DePaulo, B. M. (1991). Interpersonal analysis of the help-seeking process. Handbook of social and clinical psychology, 162, 350-375. 
APPENDICES: Appendix A

Crowne-Marlow Measure of Social Desirability Scale 
Read each item and decide as quickly as possible whether it is true $(\mathrm{T})$ or false $(\mathrm{F})$ for you.

1. T F Before voting I thoroughly investigate the qualifications of all the candidates.

2. T F I never hesitate to go out of my way to help someone in trouble.

3. T F It is sometimes hard for me to go on with my work if I am not encouraged.

4. T F I have never intensely disliked anyone.

5. T F On occasions I have had doubts about my ability to succeed in life.

6. T F I sometimes feel resentful when I don't get my way.

7. T F I am always careful about my manner of dress.

8. T F My table manners at home are as good as when I eat out in a restaurant.

9. T F If I could get into a movie without paying and be sure I was not seen, I would probably do it.

10. T F On a few occasions, I have given up something because I thought too little of my ability.

11. T F I like gossip at times.

12. $\mathrm{T} \mathrm{F}$ There have been times when I felt like rebelling against people in authority even though I knew they were right.

13. T F No matter who I'm talking to, I'm always a good listener.

14. T F I can remember "playing sick" to get out of something.

15. T F There have been occasions when I have taken advantage of someone.

16. T F I'm always willing to admit it when I make a mistake.

17. T F I always try to practice what I preach.

18. T F I don't find it particularly difficult to get along with loudmouthed, obnoxious people.

19. T F I sometimes try to get even rather than forgive and forget.

20. T F When I don't know something I don't mind at all admitting it.

21. T F I am always courteous, even to people who are disagreeable.

22. $T$ F At times I have really insisted on having things my way. 
23. $\mathrm{T} F$ There have been occasions when I felt like smashing things.

24. T F I would never think of letting someone else be punished for my wrong-doings.

25. T F I never resent being asked to return a favor.

26. T F I have never been irked when people expressed ideas very different from my own.

27. $T$ F I never make a long trio without checking the safety of my car.

28. T F There have been times when I was quite jealous of the good fortune of others.

29. T F I have never felt the urge to tell someone off.

30. T F I am sometimes irritated by people who ask favors of me.

31. T F I have never felt that I was punished without cause.

32. T F I sometimes think when people have misfortune they only got what they deserved.

33. T F I have never deliberately said something that hurt someone's feelings.

(Crowne, \& Marlow, 1960) 
Appendix B

Bem's Sex-Role Inventory 
Rate yourself on each item on a scale from 1 (never or almost never true) to 7 (almost always true).

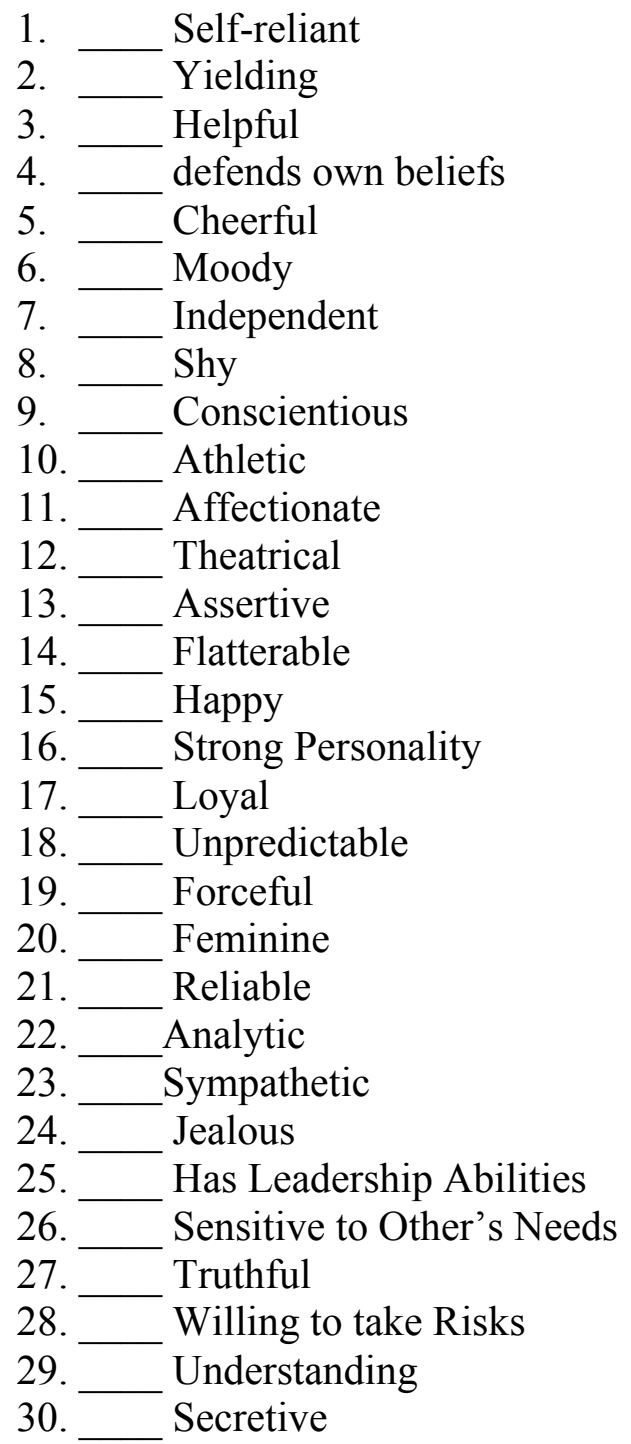

\begin{tabular}{|c|c|}
\hline 31. & Makes Decisions Easily \\
\hline 32. & Compassionate \\
\hline 33. & Sincere \\
\hline 34. & Self-Sufficient \\
\hline 35. & Eager to Soothe Hurt Feelings \\
\hline 36. & Conceited \\
\hline 37. & Dominant \\
\hline 38. & Soft-Spoken \\
\hline 39. & Likable \\
\hline 40. & Masculine \\
\hline 41. & Warm \\
\hline 42. & Solemn \\
\hline 43. & Willing to Take a Stand \\
\hline 44. & Tender \\
\hline 45. & Friendly \\
\hline 46. & Aggressive \\
\hline 47. & Gullible \\
\hline 48. & Inefficient \\
\hline 49. & Acts as a Leader \\
\hline 50. & Childlike \\
\hline 51. & Adaptable \\
\hline 52. & Individualistic \\
\hline 53. & Does Not Use Harsh Language \\
\hline 54. & Unsystematic \\
\hline 55. & Competitive \\
\hline 56. & Loves Children \\
\hline 57. & Tactful \\
\hline 58. & Ambitious \\
\hline 59. & Gentle \\
\hline 60 & Conventional \\
\hline
\end{tabular}

(Bem, 1977) 
Appendix C

Clinical Vignettes 
Casey is a medic in the Marine Corps who has returned from his deployment in the Middle East. While in working in a field hospital Casey was exposed to a large number of gun shot wounds, gruesome injuries, and witnessed many people lose their lives. For the past month and a half, Casey has had trouble sleeping. He also reports having reoccurring nightmares about the people who he was unable to save, as well as vivid depictions of the gruesome injuries he treated. Casey has talked about how he can't watch violent movies, or talk to his other friends who were also medics because it brings up too many distressing memories and feelings for him. He also feels like it was his fault that he was not able to save all of the people he treated. He has explicitly expressed that he feels ashamed because he thinks he could have done more to prevent them from dying. Casey also reports that he has trouble concentrating, and finds himself being easily startled. Casey has been diagnosed with posttraumatic stress disorder.

\section{Vignette 2. Male, Civilian PTSD Vignette}

Casey is a trauma nurse who had been working at a large hospital that is just outside of a violent area. While in working in the hospital, Casey was exposed to a large number of gun shot wounds, gruesome injuries, and witnessed many people lose their lives. For the past month and a half, Casey has had trouble sleeping. He also reports having reoccurring nightmares about the people who he was unable to save, as well as vivid depictions of the gruesome injuries he treated. Casey has talked about how he can't watch violent movies, or talk to his other friends who were also working in the emergency room because it brings up too many distressing memories and feelings for him. He also feels like it was his fault that was not able to save all of the people he treated. He has explicitly expressed that he feels ashamed because he thinks he could have done more to prevent them from dying. Casey also reports that he has trouble concentrating, and finds himself being easily startled. Casey has been diagnosed with posttraumatic stress disorder.

\section{Vignette 3. Female, Military, PTSD Vignette}

Casey is a medic in the Marine Corps who has returned from her deployment in the Middle East. While in working in a field hospital Casey was exposed to a large number of gun shot wounds, gruesome injuries, and witnessed many people lose their lives. For the past month and a half, Casey has had trouble sleeping. She also reports having reoccurring nightmares about the people who she was unable to save, as well as vivid depictions of the gruesome injuries she treated. Casey has talked about how she can't watch violent movies, or talk to her other friends who were also medics because it brings up too many distressing memories and feelings for her. She also feels like it was her fault that she was not able to save all of the people he treated. She has explicitly expressed that she feels ashamed because she thinks she could have done more to prevent them from dying. Casey also reports that she has trouble concentrating, and finds herself being easily startled. Casey has been diagnosed with posttraumatic stress disorder.

Vignette 4. Female, Civilian, PTSD Vignette 
Casey is a trauma nurse who had been working at a large hospital that is just outside of a violent area. While in working in the hospital, Casey was exposed to a large number of gun shot wounds, gruesome injuries, and witnessed many people lose their lives. For the past month and a half, Casey has had trouble sleeping. She also reports having reoccurring nightmares about the people who she was unable to save, as well as vivid depictions of the gruesome injuries she treated. Casey has talked about how she can't watch violent movies, or talk to her other friends who were also medics because it brings up too many distressing memories and feelings for her. She also feels like it was her fault that she was not able to save all of the people he treated. She has explicitly expressed that she feels ashamed because she thinks she could have done more to prevent them from dying. Casey also reports that she has trouble concentrating, and finds herself being easily startled. Casey has been diagnosed with posttraumatic stress disorder. 
Appendix D

Measures of Social Distancing 
Using the four-point scale select the appropriate number that corresponds to your beliefs about Casey, the individual depicted in the vignette. Only select one number for each statement.

(0) Definitely Unwilling (1) Somewhat Unwilling (2) Somewhat Willing (3) Definitely Willing

1. How would you feel about renting a room in your home to someone like Casey?

2. How about as a worker on the same job as someone like Casey?

3. How would you feel having someone like Casey as a neighbor?

4. How about as a caretaker of your children for a couple hours?

5. How about having your children marry someone like Casey?

6. How would you feel about introducing Casey to a person you are friendly with?

7. How would you feel about recommending someone like Casey for a job working for a friend of yours?

Adopted from (Link, Cullen, Frank, \& Wozniak,1987). 
Appendix E

Measures of Perceived Dangerousness 
8. If a group of individuals like Casey lived near by, I would not allow my children to go to the movie theater alone. (Reverse Score)

9. If someone like Casey applied for a teaching position at an elementary school and was qualified for the job I would recommend hiring them.

10. One important thing about individuals like Casey is that you cannot tell what they are going to do from one moment to the next. (Reverse Score)

11. If I know a person has had PTSD I will be less likely to trust them. (Reverse Score)

12. The main purpose of mental health providers should be to protect the public from people with PTSD. (Reverse Score)

13. If a person who previously had PTSD lived near by, I would be hesitant to allow young children under my care to play on the sidewalk.

14. Although some people with PTSD may seem all right, it is dangerous to forget for a moment that they are mentally ill. (Reverse Score)

15. There should be a law that forbids individuals who were previously diagnosed with PTSD to obtain a hunting license. (Reverse Score)

Adopted from (Link, Cullen, Frank, \& Wozniak,1987) 
Appendix F

Demographic Questionnaire 
The following questions will ask about yourself, as well as your background. The information gathered will remain anonymous and confidential. Read each question and mark, or write in the appropriate response.

1. What is your sex? Male Female

2. What is your age?

3. What is the highest level of education you have completed? Circle one.

High School Some graduate study

Some college Master's degree

Associate's degree Bachelor's degree

Other

4. What is your ethnic background? Select all that apply.

African American

Asian/Pacific Islander

Caucasian

Hispanic

Other

5. Have you ever sought help from a mental health professional?

Yes No

6. Has a member of your family or someone close to you sought help from a mental health professional?

Yes No

7. Have you ever been diagnosed with a mental health problem?

Yes No

8. Has a member of your family or someone close to you ever been diagnosed with a mental health problem?

Yes No

10. Are you a veteran or a member of the United States Armed forces?

Yes No

Adopted from (Daoud, 2009) 
Appendix G

Informed Consent 


\section{Informed Consent Form}

INFORMED CONSENT TO PARTICIPATE IN A RESEARCH PROJECT, “The Effect of Gender and Veteran Status on the Level of Perceived Stigma Surrounding PTSD.“

A research project on post traumatic stress disorder is being conducted by Ryan Lubock, a graduate student, in the Department of Psychology and Child Development at Cal Poly, San Luis Obispo under the supervision of Dr. Michael Selby. The purpose of the study is to determine the effect gender and veteran status plays in the perceived stigma of individuals diagnosed with PTSD.

You are being asked to take part in this study by completing the following questionnaire. You will be asked to read a brief vignette, and complete a questionnaire. Your participation will take approximately 20 to 25 minutes. Please be aware that you are not required to participate in this research, you may omit any items that you prefer not to answer, and you may discontinue your participation at any time without penalty or loss of benefits.

There are no risks anticipated with participation in this study. However, if you feel uncomfortable reading the vignette about the trauma the individual was exposed to that lead to their diagnosis of PTSD, please be aware that you may contact the Cal Poly Counseling Center at (805) 756-6525 for assistance. The Cal Poly Counseling Center is located in building 27, in room 135.

Your responses will be provided anonymously to protect your privacy. Potential benefits associated with the study include learning more about your own views towards individuals with PTSD. Participation in this study will also help advance the body of research around PTSD, and better understand why it is stigmatized, and how we can decrease the stigmatization of individuals with PTSD. As an incentive, you can earn one point of extra credit, or have the option to write a shorter paper for the PSY 202 class through the SONA website.

If you have questions regarding this study or would like to be informed of the results when the study is completed, please feel free to contact Ryan Lubock at (949) 338-0062, or rlubock@calpoly.edu. If you have concerns regarding the manner in which the study is conducted, you may contact Dr. Michael Black, Chair of the Cal Poly Institutional Review Board, at (805) 756-2894, mblack@calpoly.edu, or Dr. Dean Wendt, Dean of Research, at (805) 756-1508,dwendt@calpoly.edu.

If you agree to voluntarily participate in this research project as described, please indicate your agreement by completing and submitting the following questionnaire. Please print a copy of this consent form now for your reference, and thank you for your participation in this research.

\author{
Yes, I volunteer. \\ (This "button" will open the survey.)
}

\author{
No, Thank you. \\ (This "button" will exit the survey.
}


Appendix H

Debriefing Statement 
Thank you for participating in this study! The purpose of this study is to assess the amount of stigmatization faced by male and female veterans and civilians who suffer from PTSD. This study will help address ways in which stigma can pose as a barrier to individuals suffering from PTSD from seeking mental health services, despite the fact that they may benefit from doing so. This study also hopes to provide insight into how a participant's gender and sex affect the level of stigma he or she places on an individual with PTSD. 